\title{
Influência do tempo de abertura dos frascos de sistemas adesivos na microinfiltração marginal em restaurações de resina composta
}

\author{
Cristiana da Costa Libório-Lago ${ }^{1}$ \\ Rebeca Barroso Bezerra ${ }^{2}$
}

\begin{abstract}
Resumo
O objetivo deste estudo in vitro foi avaliar a influência da abertura dos frascos de sistemas adesivos na microinfiltração marginal em restauraçóes de resina composta. Quatro frascos de cada sistema adesivo, Prime \& Bond NT (PBNT), Dentsply (à base de acetona) e Adper Single Bond 2 (SB2), 3M ESPE (à base de etanol/água), foram abertos diariamente (8 vezes por 15 segundos). Cento e doze cavidades classe $\mathrm{V}$, preparadas na junção cemento-esmalte das faces vestibular e lingual de terceiros molares humanos, foram divididas em oitos grupos: G1 (PBNT) e G2 (SB2), nenhum dia de abertura; G3 (PBNT) e G4 (SB2), 30 dias de abertura; G5 (PBNT) e G6 (SB2), 60 dias de abertura; G7 (PBNT) e G8 (SB2), 90 dias de abertura. As cavidades foram restauradas com resina composta e, após acabamento, polimento e termociclagem, os dentes foram imersos em corante. Cada restauração foi seccionada no sentido vestíbulo-lingual em três cortes, analisados sob lupa estereoscópica. Os resultados foram avaliados estatisticamente através de ANOVA e pelos testes de Tukey e T de Student. Não houve diferença estatisticamente significante entre os grupos, considerando o tempo de abertura dos frascos de adesivos. A microinfiltração foi maior em dentina do que em esmalte $(\mathrm{p}<0,05)$. Não houve diferença estatisticamente significante entre os sistemas adesivos quanto à capacidade de selamento e nível de microinfiltração. Pôde-se concluir que a abertura dos frascos de adesivo não promoveu um aumento da microinfiltração nas restaurações de resina composta.
\end{abstract}

Palavras-chave: Adesivos dentinários - Infiltração dentária; Solventes.

\section{INTRODUÇÃO}

Alterações que promovem uma deficiente adesão na interface dente-restauração podem provocar menor força de adesão e maior microinfiltração. Essa última, definida como a passagem, indetectável clinicamente, de bactérias, fluido, moléculas ou íons na interface dente-restauração (KIDD, 1976), é responsável pela maioria dos insucessos da odontologia restauradora, tais como manchamento marginal das restaurações estéticas, cáries recidivantes, hipersensibilidade e desenvolvimento de patologias pulpares (GOMES; PORTO NETO; LOFFREDO, 1999).

O surgimento dos sistemas adesivos, em 1967, trouxe novos rumos para a odontologia restauradora, como a possibilidade de um preparo cavitário mais conservador e o estabelecimento de uma adesão mais eficaz entre o material restaurador e a estrutura dentária (SWIFT JR; PERDIGÃO; HEYMANN,

\footnotetext{
${ }^{1}$ Mestre em Odontologia - Faculdade de Odontologia da UFBA.

${ }^{2}$ Professora Adjunta de Dentística - Departamento de Clínica Odontológica da Faculdade de Odontologia da UFBA

Correspondência para / Correspondence to:

Cristiana da Costa Libório Lago.

Av. Cardeal da Silva, n. 57, apt. 101 - Federação.

40231-305 Salvador - BA - Brasil.

Tel: (71) 3261-2601.

E-mail: crisliborio@ig.com.br
} 
1995). A interação entre as resinas compostas e os substratos dentários está diretamente associada à condição da estrutura dentária bem como aos componentes do sistema adesivo. Dentre esses componentes, os solventes utilizados têm importância fundamental, pois auxiliam no deslocamento das moléculas de água, permitindo a maior penetração dos monômeros hidrofílicos. Por outro lado, características químicas desses solventes, como a volatilidade, acabam por requerer maiores cuidados durante a manipulação e o armazenamento dos frascos de adesivo (ABATE; RODRÍGUEZ; MACCHI, 2000; GIANNINI et al., 2008; KLEIN JR et al., 2008). Além da água, que pode ser utilizada como solvente inorgânico, os principais solventes orgânicos utilizados são acetona, etanol e uma associação de etanol e água (NUNES; SWIFT JR; PERDIGÃO, 2001).

$\mathrm{Na}$ rotina de atendimento realizada no consultório odontológico, durante os procedimentos restauradores com resina composta, a abertura dos frascos de adesivo é realizada com certa frequência. Essa abertura diária dos frascos de adesivo e a consequente volatilização desses solventes podem interferir no estabelecimento e na qualidade da adesão entre a resina e a estrutura dentária (REIS et al., 2003).

A acetona apresenta menor temperatura de evaporação $\left(56,5^{\circ} \mathrm{C}\right)$ e maior pressão de vapor $(180 \mathrm{mmHg})$ do que o etanol e a água. Pode, entretanto, provocar o colapso das fibras colágenas, quando usada sobre a dentina seca, requerendo, por isso, atuação sobre a dentina úmida (PASHLEY; CARVALHO, 1997; HASHIMOTO et al., 2002; PASHLEY et al., 2002; MANSO et al., 2008). O etanol possui temperatura de evaporação de $78,3^{\circ} \mathrm{C}$ e pressão de vapor de 43,9mmHg. Quando associado à água, como solvente inorgânico, além da maior estabilidade da solução, a água presente no sistema adesivo pode promover a reidratação das fibras colágenas, impedindo o seu colapso, aumentando a permeação do adesivo (PASHLEY; CARVALHO, 1997; PASHLEY et al., 2002). A micromorfologia da interface dente-resina, como as características dos tags e da camada híbrida, a força de adesão e a microinfiltração podem sofrer alterações em função dos solventes utilizados (LOPES et al., 2001; GREGOIRE; AKON; MILLLAS, 2002; CHUANG et al., 2006; KLEIN JR et al., 2008).

Além disso, ao se analisar o mecanismo de adesão, é importante considerar outros fatores que certamente influenciam nesse complexo mecanismo, como as diferenças estruturais e bioquímicas entre esmalte e dentina, bem como as alterações dimensionais sofridas por esses substratos durante o processo de desmineralização, e a carga de cada sistema adesivo (CARVALHO et al., 1996; PASHLEY; CARVALHO, 1997; GOMES; PORTO NETO; LOFFREDO, 1999; LOPES et al., 2001; GREGOIRE; AKON; MILLLAS, 2002). Considerando o estabelecimento da adesão, bem como os componentes e as características dos sistemas adesivos, a hidrofilicidade pode ser considerara como fator determinante para a extensão da sorção da água e a consequente formação da camada híbrida. Os solventes presentes nos sistemas adesivos aumentam essa capacidade de sorção. Estudos ainda são necessários para investigar as características de sorção e solubilidade dos adesivos, quando dissolvidos em solventes orgânicos, bem como o efeito desses solventes sobre as propriedades físicas dos sistemas adesivos (YIU et al., 2004). Dessa forma, o presente estudo se propôs a avaliar a hipótese de que a repetida abertura dos frascos de diferentes sistemas adesivos favoreceria a volatilização dos solventes presentes em suas composições, interferindo no estabelecimento da adesão, aumentando, dessa forma, a microinfiltração marginal das restauraçôes de resina composta.

\section{MATERIAIS E MÉTODOS}

Após a aprovação pela Comissão de Ética em Pesquisa da Universidade Federal da Bahia (UFBA), foram selecionados 56 terceiros molares humanos hígidos, recém-extraídos por indicação ortodôntica, periodontal, ou cirúrgica, nos quais foram realizadas raspagem com cureta periodontal e profilaxia com escova de Robinson e pasta de pedra pomes e água, para remoção de 
cálculo e de tecido aderido. Os dentes foram examinados visualmente em lupa com aumento de 2 vezes de magnitude, para confirmar a ausência de alterações estruturais, como fraturas e fissuras, sendo conservados em água destilada a $37^{\circ} \mathrm{C}$, com troca semanal, para se manterem hidratados até o momento da sua utilização.

Cento e doze cavidades do tipo classe $\mathrm{V}$ ( $2 \mathrm{~mm}$ de profundidade, $3 \mathrm{~mm}$ de altura e $5 \mathrm{~mm}$ de largura) foram confeccionadas nas faces vestibular e lingual, com margem oclusal situada em esmalte e margem cervical situada em cemento, a uma distância de, aproximadamente, 1 a $2 \mathrm{~mm}$ além da junção amelo-cementária, por se tratar de uma área crítica à microinfiltração. As cavidades foram confeccionadas em alta rotação, sob refrigeração, utilizando-se a ponta diamantada cônica topo arredondada no 2136 (KG Sorensen), sendo as mesmas descartadas a cada cinco preparos, para que mantivessem a excelência do corte. Para a padronização dos preparos, foram utilizados um paquímetro digital e uma sonda periodontal milimetrada. Os sistemas adesivos empregados para confecção das restaurações foram o Prime \& Bond NT (Dentsply), à base de acetona, e o Adper Single Bond 2 (3M ESPE), à base de etanol-água. Todas as unidades experimentais foram restauradas com resina composta híbrida Filtek Z250 (3M ESPE), na cor A3.

Visando a reproduzir a rotina clínica do cirurgião-dentista, foi feita uma estimativa do tempo médio de 15 segundos de abertura durante a utilização dos frascos de adesivos em cada procedimento restaurador e da quantidade média de restauração que é realizada em um consultório (4 pacientes em cada turno; totalizando 8 pacientes/dia), resultando em uma frequência de abertura diária de 8 vezes com 15 segundos de duração e intervalo de 1 hora. As amostras foram divididas em 8 grupos $(\mathrm{n}=14)$. Os grupos de número ímpares $(1,3,5,7)$ foram restaurados com o sistema adesivo Prime $\&$ Bond NT (Dentsply), e os grupos de números pares (2, 4, 6 e 8), com Adper Single Bond 2 (3M ESPE), à base de etanol e água. Os períodos de abertura dos frascos foram 0, 30, 60 e 90 dias. Para que o último dia de abertura de todos os grupos coincidissem, permitindo que as demais etapas do experimento fossem realizadas simultaneamente, os grupos 7 e 8 foram abertos do $1^{\circ}$ ao $90^{\circ}$ dia, totalizando 90 dias de abertura; os grupos 5 e 6 foram abertos do $30^{\circ}$ ao $90^{\circ}$ dia, totalizando 60 dias de abertura; os grupos 3 e 4 foram abertos do $60^{\circ}$ ao $90^{\circ}$ dia, totalizando 30 dias de abertura e, nos grupos 1 e 2, os sistemas adesivos foram utilizados sem ter passado por nenhum período de abertura. Inicialmente, foi realizada profilaxia com escova de Robinson e uma mistura de pedra pomes e água. Para o condicionamento das paredes cavitárias, foi aplicado ácido fosfórico a 35\% (3M ESPE). A aplicação foi iniciada pelas superfícies em esmalte, seguindo-se as superfícies dentinárias, quando, após o completo preenchimento da cavidade, foi iniciada a contagem do tempo de 10 segundos, totalizando 15 segundos de condicionamento. Em seguida, as superfícies foram lavadas com spray de ar e água por 15 segundos, e, então, secadas com papel absorvente, para melhor controle da unidade. A aplicação dos sistemas adesivos foi feita com aplicadores descartáveis (microbrush - KG Sorensen), segundo recomendações do fabricante. A inserção da resina composta foi realizada, utilizando-se espátula de titânio (Millennium), através da técnica incremental oblíqua, em um total de 3 incrementos, considerando o fator de configuração cavitária e visando à diminuição da tensão de contração de polimerização da resina composta e, consequentemente, da microinfiltração. A fotopolimerização foi realizada durante 20 segundos em cada incremento, com o aparelho Fotopolimerizados Ultralux (Dabi Atlante) e com densidade de potência de $500 \mathrm{~mW} / \mathrm{cm}^{2}$, previamente aferido com radiômetro. Após armazenamento por 24 horas em água destilada, foi realizado o acabamento e polimento das restaurações com lâminas de bisturi no $15 \mathrm{C}$ (Surgical Blade) e discos de óxido de alumínio Sof-Lex (3M ESPE), em ordem decrescente de abrasividade, em baixa rotação, que foram descartados a cada três restauraçôes. Todas as amostras foram submetidas à ciclagem térmica, num total de 500 ciclos com temperatura de $5^{\circ} \mathrm{C}+2^{\circ}$ e $55^{\circ} \mathrm{C}+2^{\circ}$, com duração de 30 segundos de imersão e intervalo de 5 segundos 
Figura 1. Dente do grupo 1 antes da imersão em corante.

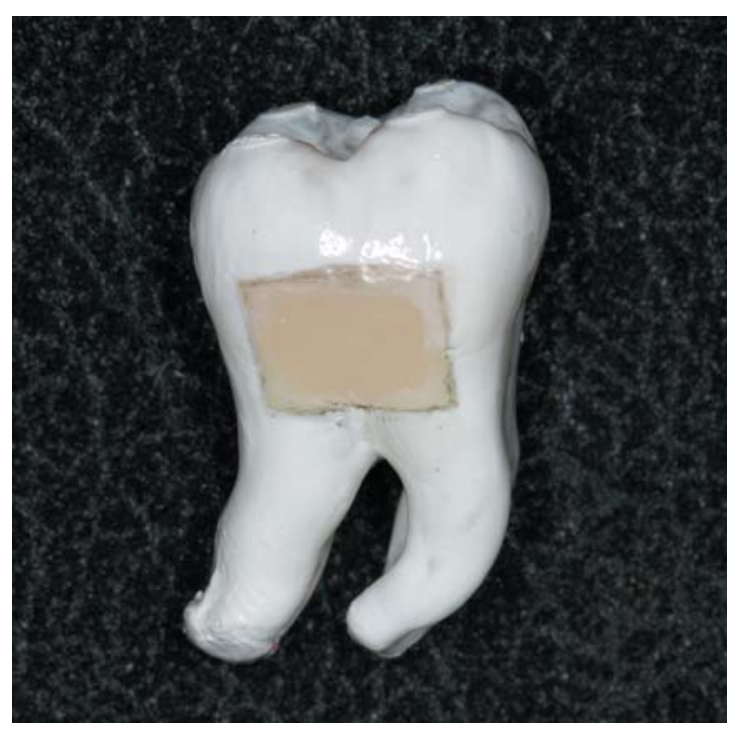

Figura 2. Dente do grupo 1 após a imersão em corante.

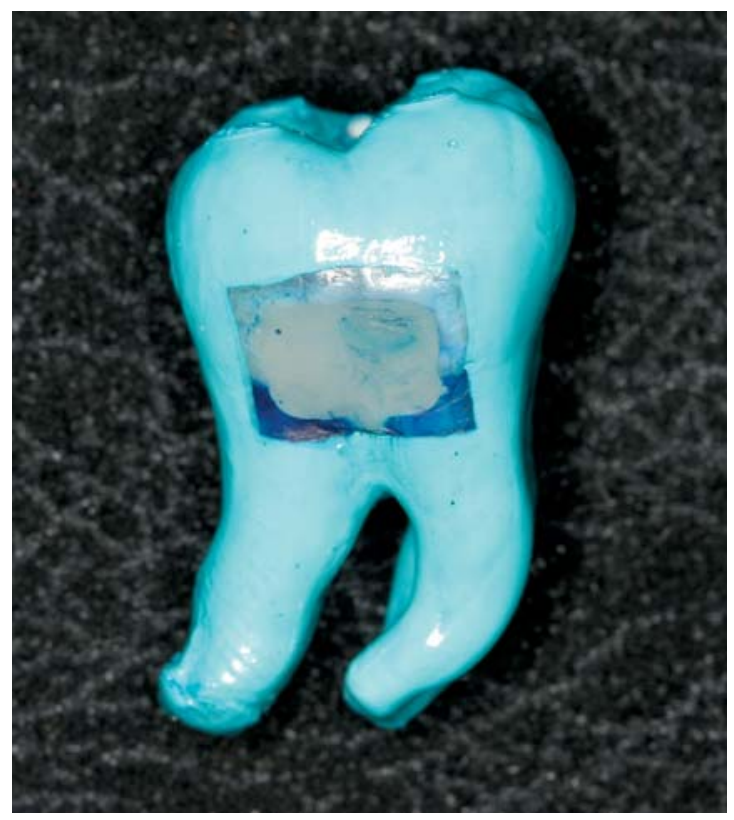

entre os banhos. Em seguida, para evitar que a infiltração retrógrada ocorresse via forame apical ou através de fissuras, os ápices radiculares foram vedados com resina composta, e todas as demais áreas foram impermeabilizadas com duas camadas de esmalte para unhas (Niasi), a uma distância de $1 \mathrm{~mm}$ das margens da restauração. As amostras foram imersas em solução aquosa de azul de metileno a $0,5 \%$, por 24 horas, a
Figura 3. Microinfiltração ausente em esmalte e com $0,5 \mathrm{~mm}$ em dentina.

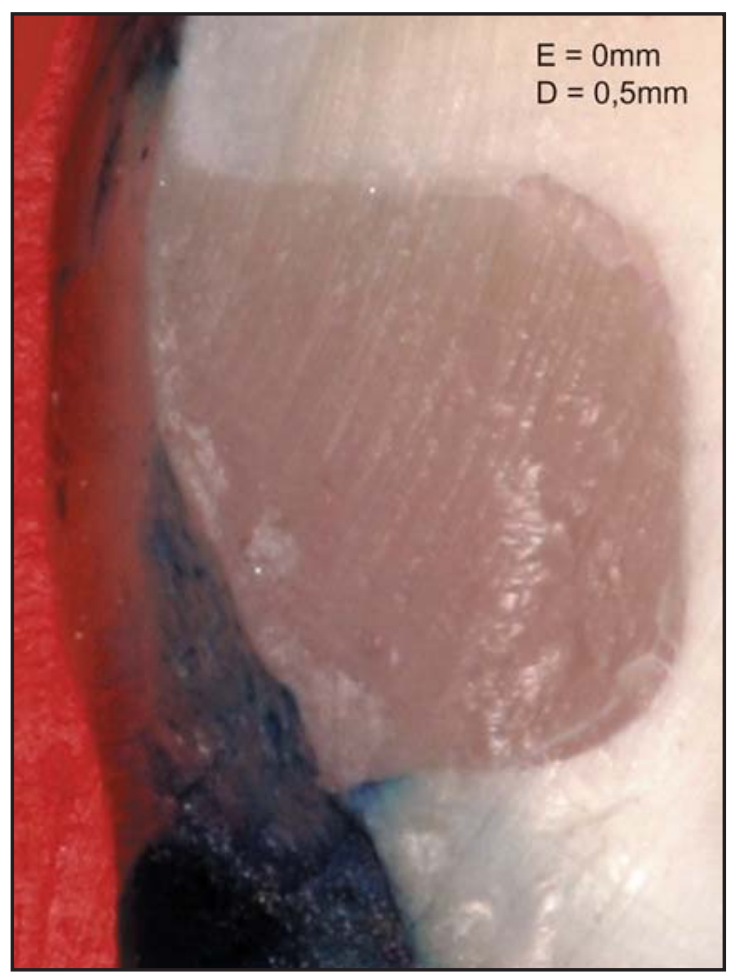

$37^{\circ} \mathrm{C}$ (Figura 1; Figura 2). Após esse período, os dentes foram lavados em água corrente, por 15 minutos. Em seguida, todo o esmalte utilizado para impermeabilização foi removido por raspagem. Cada restauração foi então seccionada em 3 partes, para posterior análise.

Para que a leitura fosse realizada de forma a caracterizar um estudo cego, uma nova numeração, estabelecida aleatoriamente, foi atribuída a cada espécime, procedendo-se, então, à leitura realizada por dois avaliadores previamente treinados. Para avaliação da microinfiltração, foram utilizados uma lupa estereoscópica (Zeiss), com 20 vezes de aumento, e um paquímetro digital eletrônico (Digimess), sendo atribuídos valores absolutos determinados em milímetros com o paquímetro (Figura 3). Os dados obtidos foram tabelados e analisados estatisticamente. Para tal, foram utilizadas medidas de tendência central e de dispersão, a fim de descrever os dados por grupo. Após a identificação da distribuição normal, para comparação da microinfiltração em cada substrato (esmalte e dentina), em função do 
tempo de abertura dos frascos de adesivos e em função dos sistemas adesivos testados, foram utilizados a ANOVA e o teste de Tukey. Para a comparação em função dos substratos, em cada período, aplicou-se o teste T de Student. Todas as análises foram calculadas considerando-se um intervalo de confiança de 95\%.

\section{RESULTADOS}

Apesar de, nos grupos restaurados com Prime \& Bond NT (1, 3, 5 e 7), tanto em esmalte (Gráfico 1) como em dentina (Gráfico 2 ), observar-se que houve um aumento da microinfiltração em esmalte, a análise estatística (teste de Tukey 95\%), em função do tempo de abertura de 0,30, 60 e 90 dias, demonstrou não haver diferença estatisticamente significante entre os grupos, bem como para os grupos restaurados com o Adper Single Bond 2 (2, 4, 6 e 8).

Para a comparação da microinfiltração entre os sistemas adesivos utilizados, o teste de Tukey 95\% também demonstrou não haver diferença estatisticamente significante entre o Prime \& Bond NT (Dentsply) e o Adper Single Bond 2 (3M ESPE), tanto em esmalte (Gráfico 1) como em dentina (Gráfico 2).

Quanto à microinfiltração em esmalte e dentina, o teste $\mathrm{T}$ de Student demonstrou haver diferença estatisticamente significante entre esmalte e dentina de toda a amostra e nos grupos 1, 3, 4, 6 e 8, tendo a dentina um maior grau de infiltração (Tabela 1).

\section{DISCUSSÃO}

A hipótese inicial deste estudo foi rejeitada, uma vez que os resultados, apesar de terem demonstrado um aumento $\mathrm{da}$ microinfiltração, não mostraram diferenças estatisticamente significantes. É importante considerar, para esta análise, a complexidade do mecanismo de adesão, bem como a composição e sensibilidade dos sistemas adesivos utilizados na técnica empregada.

As propriedades químicas dos solventes utilizados neste estudo, acetona (Prime $\&$ Bond NT; Dentsply) e etanol/água (Adper Single
Gráfico 1. Média e intervalo de confiança 95\% da microinfiltração $(\mathrm{mm})$ em esmalte por grupo.

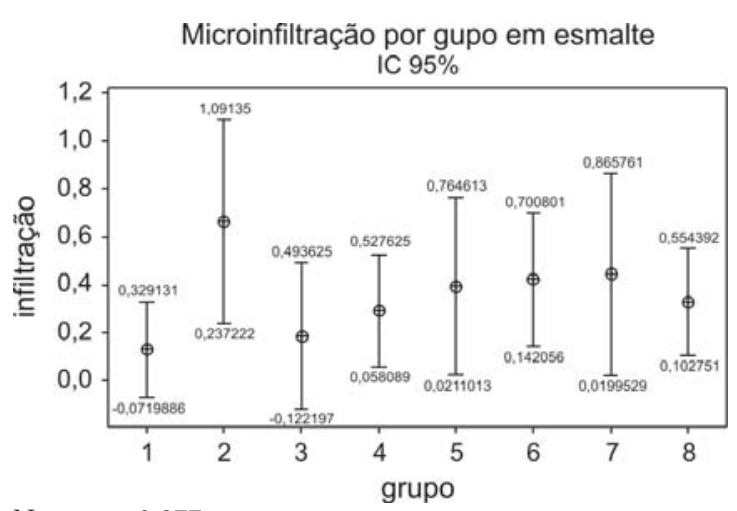

Nota: $\mathrm{p}=0,277$.

Gráfico 2. Média e intervalo de confiança 95\% da microinfiltração $(\mathrm{mm})$ em dentina por grupo.

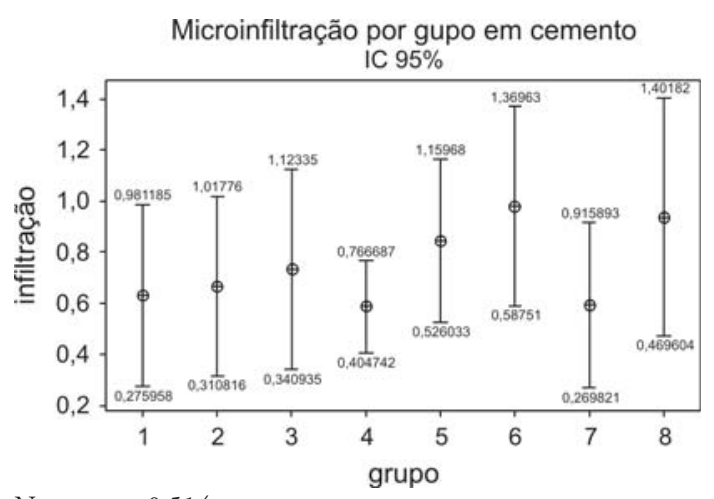

Nota: $\mathrm{p}=0,514$.

Tabela 1. Comparação da microinfiltração entre esmalte e dentina obtida através do teste $\mathrm{T}$ de Student.

\begin{tabular}{lccl}
\hline & Esmalte & Dentina & \multicolumn{1}{c}{$\mathbf{P}$} \\
\hline Toda a amostra & 0,357 & 0,745 & $0,000^{*}$ \\
Grupo 1 & 0,129 & 0,629 & $0,015^{*}$ \\
Grupo 2 & 0,664 & 0,664 & 1,000 \\
Grupo 3 & 0,186 & 0,732 & $0,026^{*}$ \\
Grupo 4 & 0,293 & 0,586 & $0,043^{*}$ \\
Grupo 5 & 0,393 & 0,843 & 0,058 \\
Grupo 6 & 0,421 & 0,979 & $0,020^{*}$ \\
Grupo 7 & 0,443 & 0,593 & 0,548 \\
Grupo 8 & 0,329 & 0,936 & $0,021^{*}$ \\
\hline Nota: * valor estatisticamente significante $(\mathrm{p}<0,05)$.
\end{tabular}


Bond 2; 3M ESPE), exercem uma influência direta no estabelecimento da adesão. Por apresentar menor temperatura de evaporação $\left(56,5^{\circ} \mathrm{C}\right)$, a acetona estaria mais sujeita aos efeitos da volatilidade, que ocorreriam com a abertura dos frascos de adesivos, do que o etanol, que possui temperatura de evaporação de $78,3^{\circ} \mathrm{C}$. Entretanto, o resultado deste estudo, corroborando outros trabalhos revistos na literatura (LOPES et al., 2001; GREGOIRE; AKON; MILLLAS, 2002; CHUANG et al., 2006), parece demonstrar que esse parâmetro não exerce efeito determinante no estabelecimento da adesão, ou ainda que outros fatores poderiam mascarar o efeito desta volatilização. Por isso, é importante considerar ainda que, apesar da menor temperatura de volatilidade, a acetona possui pressão de vapor de $180 \mathrm{mmHg}$, bem maior do que a do etanol, apenas $43,9 \mathrm{mmHg}$, o que, por sua vez, confere à acetona uma maior capacidade de diminuir a viscosidade da solução (aumentando o poder de penetração do sistema adesivo na dentina desmineralizada), diminuir a tensão superficial da água (deslocando-a dos túbulos dentinários) e remover a água da superfície das fibras colágenas (permitindo maior embricamento dos sistemas adesivos para estas regiōes) (PASHLEY; CARVALHO, 1997; HASHIMOTO et al., 2002; PASHLEY et al., 2002). É importante salientar ainda que, apesar de a acetona apresentar uma menor temperatura de evaporação, ainda assim, ela é muito superior à temperatura ambiente, na qual foi desenvolvido o presente estudo, e que o formato dos frascos dos sistemas adesivos é projetado para permitir uma mínima evaporação dos solventes (REIS et al., 2003).

É necessário considerar, portanto, a influência simultânea de outros fatores. A dificuldade em se controlar a umidade dentinária é abordada por muitos estudos e, consequentemente, responsável pela grande variação nos resultados obtidos, mesmo em estudos semelhantes (PASHLEY; CARVALHO, 1997; PERDIGÃO et al., 1999; LOPES et al., 2001; GREGOIRE; AKON; MILLAS, 2002; REIS et al., 2003; BALKENHOL et al., 2007). Se, por um lado, em relação ao esmalte, a umidade parece não exercer efeito significante (CHUANG et al., 2006), por outro, a água mantida na dentina úmida (ou aplicada com os sistemas adesivos que contêm água na sua composição) é importante para impedir o colapso da rede de fibras colágenas, mantendoas expandidas, preservando espaço para a penetração dos monômeros hidrofílicos (PASHLEY; CARVALHO, 1997; PASHLEY et al., 2002). Entretanto, o excesso de umidade pode reduzir a penetração dos monômeros, uma vez que a água ocuparia os espaços desmineralizados no interior da dentina (PERDIGÃO et al., 1999). A falta de controle da quantidade de água suficiente para deixar a dentina úmida pode levar pesquisadores a interpretar seus resultados em um espectro de umidade no qual variações do parâmetro pesquisado não seriam constatadas (REIS et al., 2003). Nesse contexto, em uma mesma cavidade, áreas de sobreumidecimento e regiōes com falta de umidade podem ser observadas (LOPES et al., 2001).

Ao se considerar ainda a presença de água na composição dos sistemas adesivos, o Adper Single Bond 2 seria menos sensível a essas variaçôes na umidade dentinária, uma vez que a água presente na sua composição promoveria a re-expansão da rede de fibras colágenas, impedindo o colapso da mesma. Entretanto, a concentração da água presente no Single Bond (3 a 8\%, segundo informações do fabricante) pode não ser suficiente para expandir a rede de fibras colágenas e permitir a penetração do adesivo (PERDIGÃO et al., 1999), ou ainda é importante considerar que a quantidade de água requerida para re-expandir as fibras colágenas pode ser específica para cada sistema adesivo (REIS et al., 2003). Dessa forma, uma nova abordagem dos sistemas adesivos passa, portanto, a ser considerada: a concentração ideal de água presente na sua composição que seria necessária para, de fato, impedir o colapso das fibras colágenas. Segundo estudos (CARVALHO et al., 1996), essa concentração seria entre 9 e 50\%, valores muito acima das concentrações encontradas nos atuais sistemas adesivos. Tais informaçōes tornam questionável, portanto, a eficácia desses sistemas adesivos que contêm 
etanol/água como solvente, quando essa eficácia é atribuída principalmente à água presente na sua composição. Alguns autores (HASHIMOTO et al., 2002) sugeriram que, dentre os adesivos à base de acetona, o Prime $\&$ Bond NT parece ser menos sensível às variações da umidade dentinária. Quando sistemas adesivos que contêm água são utilizados sobre a dentina seca, dois eventos podem ocorrer: se a concentração de água no sistema adesivo for muito baixa, antes de ocorrer a re-expansão das fibras colágenas, os solventes e a resina presentes nos sistemas adesivos promoverão um enrijecimento das fibras colágenas. Entretanto, se houver quantidade de água suficiente, a re-expansão das fibras colágenas ocorrerá antes do enrijecimento, permitindo, assim, maior penetração dos monômeros hidrofílicos dos sistemas adesivos para a zona desmineralizada. Por outro lado, uma quantidade excessiva de água também não seria benéfica, uma vez que, além de promover uma rápida re-expansão das fibras colágenas, também promoveria uma maior diluição dos monômeros (PASHLEY; CARVALHO, 1997). São dados que sugerem que a sensibilidade do Adper Single Bond 2 ao nível de umidade dentinária parece, portanto, ser tão intensa quando a do Prime \& Bond NT, e que o nível de umidade considerado ótimo para o Prime $\&$ Bond NT certamente não seria o mesmo para Adper Single Bond 2.

Quanto aos demais componentes presentes nos sistemas adesivos que influenciam no mecanismo de adesão, pode-se destacar a sua carga. Nos sistemas adesivos testados neste experimento, ambos se diferenciam dos seus antecessores por possuírem nanopartículas na sua composição, o Prime \& Bond NT (Dentsply) de $7 \mathrm{~nm}$ e o Adper Single Bond 2 (3M ESPE), de $5 \mathrm{~nm}$, segundo informações do fabricante. A inclusão de nanopartículas permite uma maior permeação nos túbulos dentinários e melhor adaptação das resinas às paredes dos túbulos, reforçando os tags e a camada híbrida (GREGOIRE; AKON; MILLAS, 2002).

De acordo com a maioria dos trabalhos revistos na literatura (GOMES; PORTO NETO; LOFFREDO, 1999; LOPES et al.,
2001), quanto à diferença da capacidade de selamento no esmalte e na dentina, este estudo demonstrou uma maior microinfiltração em dentina do que em esmalte. Entretanto, é importante considerar, para a análise da adesão, que diferenças químicas e estruturais na composição da dentina, como orientação das fibras colágenas e direção dos túbulos, pode variar de acordo com a idade, localização ou outros fatores inerentes a cada unidade dentária (MARSHALL et al., 1997). Dessa forma, esses relatos, de grande implicação clínica, devem ser levados em consideração ao se analisarem os resultados deste estudo, no qual valores de microinfiltração bem variados foram observados dentro de um mesmo grupo ou de uma mesma restauração.

Tais resultados refletem a nãouniformidade da adesão dentro de uma mesma restauração, o que, além dos fatores discutidos anteriormente, pode ocorrer em consequência de variações na espessura da smear layer, diferentes níveis de profundidade de desmineralização pelo condicionamento ácido e tensão de contração de polimerização (PASHLEY; CARVALHO, 1997).

Vale salientar as limitações dos estudos in vitro, ressaltando a importância da realização de estudos em situaçôes onde se reproduzam condiçôes clínicas, como a pressão intra-pulpar, a temperatura e a presença de fluidos nos túbulos dentinários, o que pode influenciar nos procedimentos adesivos.

\section{CONCLUSÕES}

Baseando-se nas condiçôes experimentais testadas e na análise estatística dos resultados obtidos, pôde-se concluir:

- a abertura diária dos frascos dos adesivos não influenciou na microinfiltração em esmalte e em dentina;

- a microinfiltração marginal foi maior em dentina do que em esmalte;

- $\quad$ entre os adesivos Prime \& Bond NT (Dentsply) e o Adper Single Bond 2 (3M ESPE), não houve diferença quanto à capacidade de selamento e nível de microinfiltração. 


\title{
Influence of opening time of adhesive systems bottles on the marginal microleakage of composite resin restorations.
}

\begin{abstract}
The aim of this in vitro study was to evaluate the influence of repeated opening of two adhesive systems bottles, an acetone based and an ethanol/water based, on the marginal microleakage of composite resin restorations. To reproduce the clinical routine, the opening periods of 15 seconds in restoratives procedure and the amount of restorations accomplished in one day (8 patients/day) were accounted. Four adhesives system bottles, Prime \& Bond NT (PBNT), Dentsply (acetone based), and Adper Single Bond 2 (SB2), 3M ESPE (ethanol/water based) were daily opened, 8 times of 15 seconds for 0, 30, 60 and 90 days. One hundred twelve Class V cavities located at the cemento-enamel junction were prepared in bucal and lingual surfaces of human third molars and it were randomly divided into 8 groups, in which the adhesive systems were used as follows: G1: PBNT, no opening; G2: SB2, no opening; G3: PBNT, 30 days of opening; G4: SB2, 30 days of opening; G5: PBNT, 60 days of opening; G6: SB2, 60 days of opening; G7: PBNT, 90 days of opening; e G8: SB2, 90 days of opening. The cavities were restored with composite resin - Filtek $Z 250$ (3M ESPE). After finishing and the polishing teeth were thermocycled (500 cycles at $5^{\circ} \mathrm{C}+2^{\circ}$ and $\left.55^{\circ} \mathrm{C}+2^{\circ}\right)$. The radicular apices were sealed with composite resin - Filtek Z250, and the teeth were coated with fingernail varnish within $1 \mathrm{~mm}$ the margin of the restorations. The teeth were immersed in $0,5 \%$ buffered methylene blue solution for 24 hours at $37^{\circ} \mathrm{C}$ and sectioned in a bucalingual direction using a diamond disc in three sections which were inspected under a stereomicroscope using a digital pachymeter to measure the microleakage in millimeters. Statistical analysis was performed using a two-way ANOVA, Tukey's Test and T Student. There was no statistically significant difference for Prime \& Bond NT and Adper Single Bond 2 considering the periods of opening. The microleakage was higher in dentin than enamel margins $(p<0,05)$. There was no statistically significant difference among the adhesive systems about sealing ability and avoiding the microleakage. Based on the experimental conditions tested, it may be concluded that the opening of adhesive's bottles performed in clinical routine and the possible solvent volatilization didn't increase the microleakage in the composite resin restorations.
\end{abstract}

Keywords: Adhesive systems - Solvents- Dental leakage.

\section{REFERÊNCIAS}

ABATE, P.F.; RODRÍGUEZ, V.I.; MACCHI, R.L. Evaporation of solvent in one bottle adhesives. J. Dent., Kidlington, v.28, p.437440, 2000.

BALKENHOL, M. et al. Influence of solvent type in experimental dentin primer on the marginal adaptation of Class $\mathrm{V}$ restorations. J. Dent., Kidlington, v.35, n.11, p.836-844, Nov. 2007.

CARVALHO, R.M. et al. In vitro study on the dimensional changes of human dentine after demineralization. Arch. Oral Biol., Oxford, v.41, n.4, p.369-377, 1996.
CHUANG, S.F. et al. Influence of enamel wetness on resin composite restorations using various dentine bonding agents. Part I.: Effects on marginal quality and enamel microcrack formation. J. Dent., Kidlington, v.34, n.5, p.343-351, May 2006.

GIANNINI, M. et al. Effects of solvent evaporation technique on the degree of conversion of one-bottle adhesive systems. Oper. Dent., Seattle, v.33, n.2, p.149-154, 2008.

GOMES, O.M.G.; PORTO NETO, S.T.; LOFFREDO, L.C.M. Análise “in vitro" da microinfiltração marginal em cavidades de classe $\mathrm{V}$, restauradas com três diferentes sistemas adesivos. R. ABO Nac., Rio de Janeiro, v.7, n.3, p.147-151, jun./jul. 1999. 
GREGOIRE, G.L.; AKON, B.A.; MILLAS, A. Interfacial micromorphological differences in hybrid layer formation between water- and solvent-based dentin bonding systems. J. Prosthet. Dent., St.Louis, v.87, n.6, p.633-641, June 2002.

HASHIMOTO, M. et al. The extent to which resin can infiltrate dentin by acetone-based adhesives. J. Dent. Res., Alexandria, v.81, n.1, p.74-78, 2002.

KIDD, E.A.M. Microleakage: a review. J. Dent., Kidlington, v.4, n.5, p.199-206, Sept. 1976.

KLEIN JR, C.A. et al. Evaporating solvents with a warm air-stream: effects on adhesive layer properties and resin-dentin bond strengths. J. Dent., Kidlington, v.36, n.8, p.618-625, 2008.

LOPES, G.C. et al. Efeito do tipo de solvente na microinfiltração de restaurações de resina composta usando adesivos de frasco único. R. Odontol. UNESP, Marília, v.30, n.1, p.21-29, 2001.

MANSO, A.P. et al. Stability of wet versus dry bonding with different solvent-based adhesives. Dent. Mater., Kidlington, v.24, n.4, p.476482, 2008.

MARSHALL JR, G.W. et al. The dentin substrate: structure and properties related to bonding. J. Dent., Kidlington, v.25, n.6, p.441-458, Nov. 1997.
NUNES, M.F.; SWIFT JR, E.J.; PERDIGAO, J. Effects of adhesive composition on microtensile bond strength to human dentin. Am. J. Dent., San Antonio, v.14, n.6, p.340343, Dec. 2001.

PASHLEY, D.H. et al. Solvation of dried dentin matrix by water and other polar solvents. Am. J. Dent., San Antonio, v.15, n.2, p.97-102, Apr. 2002.

PASHLEY, D.H.; CARVALHO, R.M. Dentine permeability and dentine adhesion. J. Dent., Kidlington, v.25, n.5, p.355-372, Sept. 1997.

PERDIGÃO, J. et al. The effect of a rewetting agent on dentin bonding. Dent. Mater., Kidlington, v.15, p.282-295, 1999.

REIS, A.F. et al. The effect of organic solvents on one-bottle adhesives bond strength to enamel and dentin. Oper. Dent., Seattle, v.28, n.6, p.700-706, Nov./ Dec. 2003.

SWIFT JR, E.J.; PERDIGÃO, J.; HEYMANN, H.D. Bonding to enamel and dentin: a brief history and state of the art. Quintessence Int., Berlin, v.26, n.2, p.95-110, Feb. 1995.

YIU, C.K.Y. et al. Effect of resin hydrophilicity and water storage an resin strengh. Biomaterials, Oxford, v.25, p.57895796, 2004. 